\title{
Renal functional reserve in IDDM patients
}

\author{
H.Sackmann ${ }^{1}$, T. Tran-Van ${ }^{2}$, I. Tack ${ }^{2}$, H.Hanaire-Broutin ${ }^{1}$, J.-P.Tauber ${ }^{1}$, J.-L. Ader ${ }^{2}$ \\ ${ }^{1}$ Service d'Endocrinologie-Diabétologie, Rangueil University Hospital, Toulouse, France \\ ${ }^{2}$ Laboratoire d'Explorations Fonctionnelles Rénales and Unité INSERM 388, Rangueil University Hospital, Toulouse, France
}

\begin{abstract}
Summary The aim of this study was to determine whether renal functional reserve (RFR) is altered in insulin-dependent diabetic (IDDM) patients according to the stage of diabetic nephropathy. RFR was examined in 33 IDDM patients in similar glycaemic and metabolic control and compared to 12 healthy control subjects, during eight $1 \mathrm{~h}$ clearance periods prior to, during and after a 3-h stimulation by amino acid infusion $\left(4.5 \mathrm{mg} \cdot \mathrm{kg}^{-1} \cdot \mathrm{min}^{-1}\right)$. RFR was calculated as the difference between stimulated and baseline glomerular filtration rates (GFR). In 14 early normotensive diabetic patients with normal urinary albumin excretion, mean baseline GFR $\left(133 \pm 3 \mathrm{ml} \cdot \mathrm{min}^{-1}\right.$. $\left.1.73 \mathrm{~m}^{-2}\right)$ was higher whereas RFR $\left(10 \pm 4 \mathrm{ml} \cdot \mathrm{min}^{-1}\right.$. $\left.1.73 \mathrm{~m}^{-2}\right)$ was lower $(p<0.05)$ than in control subjects $\left(113 \pm 4\right.$ and $28 \pm 2 \mathrm{ml} \cdot \mathrm{min}^{-1} \cdot 1.73 \mathrm{~m}^{-2}$, respectively). In 10 normotensive patients who had lived with IDDM for 16 years and who had microalbuminuria, baseline GFR and RFR (109 \pm 7 and $24 \pm 6 \mathrm{ml}$. $\min ^{-1} \cdot 1.73 \mathrm{~m}^{-2}$, respectively) were similar to those in control subjects. In 9 patients who had suffered IDDM for 23 years and had developed macroalbuminuria and hypertension, baseline GFR (78 $\pm 8 \mathrm{ml}$.
\end{abstract}

Received: 12 February 1997 and in final revised form: $28 \mathrm{Au}$ gust 1997

Corresponding author: Dr. J.-L. Ader, Laboratoire d'Explorations Fonctionnelles Rénales et Métaboliques, $\mathrm{H}^{\wedge}$ opital de Rangueil, 1, Avenue Jean Poulhès, F-31043 Toulouse Cedex 4, France

Abbreviations: GFR, glomerular filtration rate; RFR, renal functional reserve; ERPF, effective renal plasma flow; RVR, renal vascular resistance; nA-nT, normoalbuminuric normotensive patients; $\mu \mathrm{A}-\mathrm{nT}$, microalbuminuric normotensive patients; mA-hT, macroalbuminuric hypertensive patients; CEI, converting enzyme inhibitor. $\left.\min ^{-1} \cdot 1.73 \mathrm{~m}^{-2}\right)$ was lower than in control subjects $(p<0.05)$ and $\operatorname{RFR}\left(8 \pm 4 \mathrm{ml} \cdot \min ^{-1} \cdot 1.73 \mathrm{~m}^{-2}\right)$ was not significant. In addition, renal vascular resistance decreased significantly during infusion $(p<0.05)$ in microalbuminuric normotensive patients as well as in control subjects (by $9 \pm 4$ and $11 \pm 4 \mathrm{~mm} \mathrm{Hg} \cdot \mathrm{l}^{-1}$. $\min ^{-1} \cdot 1.73 \mathrm{~m}^{-2}$, respectively) but not in normoalbuminuric normotensive or macroalbuminuric hypertensive patients. These results indicate that microalbuminuric normotensive patients retain a normal RFR, whereas RFR is reduced or suppressed at two opposite stages of the disease: in normoalbuminuric normotensive patients with a high GFR and in macroalbuminuric hypertensive patients with a decreased GFR. This dissimilar impairment reveals permanent glomerular hyperfiltration in both early IDDM without nephropathy and IDDM with overt diabetic nephropathy, but not in IDDM with incipient nephropathy. [Diabetologia (1998) 41: 86--93]

Keywords Insulin-dependent diabetes mellitus, diabetic nephropathy, renal functional reserve, glomerular filtration rate, amino acid infusion.
Renal functional reserve (RFR) is usually defined as the difference between basal or "unstimulated" " glomerular filtration rate (GFR) and "stimulated" " GFR increased by stimuli such as oral protein load $[1,2]$ or amino acid infusion [3--5]. There is general agreement that RFR reflects the capacity of the healthy kidney to achieve a higher degree of function by vasodilation of glomerular arterioles. The reduction or the absence of the so-called functional reserve in renal diseases may imply that the residual nephrons are working at maximum capacity and there is substantial evidence that such a glomerular hyperfiltra- 
Table 1. Characteristics of non-albuminuric normotensive (nA-nT), microalbuminuric normotensive ( $\mu \mathrm{A}-\mathrm{nT})$ and macroalbuminuric hypertensive (mA-hT) diabetic patients, and of control subjects

\begin{tabular}{|c|c|c|c|c|}
\hline Characteristic & nA-nT & $\mu \mathrm{A}-\mathrm{nT}$ & mA-hT & $\begin{array}{l}\text { Control } \\
\text { subjects }\end{array}$ \\
\hline Age (years) & $30.7 \pm 2.0$ & $31.6 \pm 2.2$ & $40.4 \pm 3.7^{\mathrm{a}, \mathrm{b}}$ & $27.7 \pm 1.5$ \\
\hline Duration of diabetes (years) & $2.1 \pm 0.4$ & $17.3 \pm 2.6$ & $23.4 \pm 3.0$ & - \\
\hline Protein intake (g per day) & $81.0 \pm 6.4$ & $84.4 \pm 7.9$ & $82.8 \pm 6.8$ & $77.8 \pm 11.9$ \\
\hline Fasting P-glucose (mmol/l) & $6.6 \pm 0.5$ & $7.1 \pm 0.5$ & $7.7 \pm 0.5$ & - \\
\hline Insulin dosage (IU per day) & $26 \pm 4$ & $39 \pm 4$ & $35 \pm 2$ & - \\
\hline Serum creatinine $(\mu \mathrm{mol} / \mathrm{l})$ & $85 \pm 2$ & $89 \pm 3$ & $125 \pm 11$ & $78 \pm 3$ \\
\hline Creatinine clearance $\left(\mathrm{ml} \cdot \mathrm{min}^{-1} \cdot 1.73 \mathrm{~m}^{-2}\right)$ & $139 \pm 4$ & $126 \pm 5$ & $102 \pm 9$ & $129 \pm 5$ \\
\hline P-renin (ng/l) & $10.3 \pm 1.8$ & $11.1 \pm 3.4$ & $16.0 \pm 3.0$ & $12.4 \pm 2.2$ \\
\hline P-aldosterone (ng/dl) & $9.2 \pm 1.1$ & $11.6 \pm 2.5$ & $8.4 \pm 2.1$ & $14.7 \pm 1.7$ \\
\hline
\end{tabular}

Values are means \pm SEM

${ }^{a} p<0.01$ vs control subjects

${ }^{\mathrm{b}} p<0.05$ vs nA-nT values

tion may induce a relentless functional decline and a progression toward renal failure regardless of the primary disease $[1,6]$.

The issue of whether insulin-dependent diabetic (IDDM) patients have a normal response and RFR deserves cautious attention and interpretation [7] for two main reasons. First, because RFR is dependent on the baseline GFR and therefore, on the stage of diabetic nephropathy; in particular, stimulated GFR and RFR would be assumed to be diminished in the case of supranormal GFR which is a frequent hallmark of early IDDM. And second, because both baseline GFR and RFR also strictly depend on recent dietary intakes and prevailing metabolic control of diabetes mellitus. These reasons are likely to explain why the results of previous RFR studies, that have used either an oral protein load or an amino acid infusion in partial or heterogeneous groups of diabetic patients with dissimilar protein intakes and metabolic control conditions, seem, above all, conflicting. According to groups and conditions, the reported increases in stimulated GFR were likely to be either not significant with no RFR [1, 8--13], or significant but lower than in control subjects with a reduced RFR [14], or similar to that in control subjects with a normal RFR [8, 11, 13, 15--17].

This remarkable inconsistency between previous results and the fact that no study so far has precisely considered the response to stimulation according to the degree of renal functional impairment prompted us to examine separately and to compare the ability of diabetic patients at the different stages of the disease to demonstrate a functional reserve. The aim of this study was therefore to assess, under similar metabolic conditions, the renal response of IDDM patients to amino acid infusion and to compare their ability to increase GFR with respect to the stage of diabetic nephropathy as determined by the prevailing levels of proteinuria and blood pressure.

\section{Subjects and methods}

Study subjects. The study (previously approved by the ethical review board of the Centre Hospitalier Universitaire de Toulouse, France) was carried out in 33 IDDM patients and 12 healthy control subjects. Diabetic patients were distributed among three groups according to the stage of renal involvement and nephropathy [18, 19].

Fourteen patients (11 males, 3 females) had suffered diabetes for approximately 2 years (Table 1 ). They had normal urinary albumin excretion $(2 \pm 5 \mathrm{mg} /$ day $)$ and were normotensive (mean arterial pressure: $77 \pm 2 \mathrm{~mm} \mathrm{Hg}$ ). These normoalbuminuric and normotensive patients (nA-NT) were considered to be in the "silent" " stage of preclinical renal involvement. Plasma glucose concentration in fasting patients on insulin therapy, and gross renal function, as evaluated by serum creatinine level and 24-h creatinine clearance, were normal (Table 1). They exhibited none of the extrarenal complications of diabetes.

Ten patients ( 8 males, 2 females) had lived with IDDM for approximately 17 years (Table 1 ). They exhibited microalbuminuria $(99 \pm 20 \mathrm{mg} /$ day) and had normal mean arterial pressure $(85 \pm 3 \mathrm{~mm} \mathrm{Hg})$. These microalbuminuric normotensive patients $(\mu \mathrm{A}-\mathrm{nT})$ were considered to be in the "incipient" " stage of preclinical renal involvement. Fasting plasma glucose concentration and gross renal function were normal (Table 1). Seven patients out of 10 had a low grade retinopathy, 1 had a lower limb arterial insufficiency and 1, a peripheral neuropathy. Five patients were usually maintained on stable doses of a converting enzyme inhibitor (CEI: 3 with enalapril 5 or $10 \mathrm{mg}$ per day, 1 with perindopril $4 \mathrm{mg}$ per day and one with fozinopril $10 \mathrm{mg}$ per day).

Nine patients ( 6 males, 3 females) had suffered IDDM for approximately 23 years. They had developed macroalbuminuria $(1779 \pm 432 \mathrm{mg} /$ day) and hypertension (mean arterial pressure: $111 \pm 5 \mathrm{~mm} \mathrm{Hg}$ ). These macroalbuminuric and hypertensive diabetic patients (mA-hT) were considered to be in the "overt" " stage of clinical nephropathy. Serum creatinine level was slightly elevated and creatinine clearance, slightly reduced (Table 1). All mA-hT patients had retinopathy, 1 had coronary arterial disease, 1 had a lower limb arterial insufficiency, and 3 of them, peripheral neuropathy. All of them were usually maintained on stable doses of CEI ( 7 with enalapril 5 to $15 \mathrm{mg}$ per day, 1 with ramipril $5 \mathrm{mg}$ per day and 1 with fozinopril $10 \mathrm{mg}$ per day). 
All diabetic patients had been trained with the same educational programme and were on intensified insulin therapy with either multiple daily injections (24 patients) or continuous s.c. insulin infusion with an external pump ( 9 patients). Daily insulin doses are reported in Table 1. All patients were deprived of all medication including CEI therapy, but not insulin, for at least 1 week prior to the day of the study.

Control subjects were 12 (6 males, 6 females) normoalbuminuric $(8 \pm 2 \mathrm{mg} /$ day) and normotensive (mean arterial pressure: $80 \pm 2 \mathrm{~mm} \mathrm{Hg}$ ) healthy volunteers who had given their informed consent. They were deprived of all medication and had a normal renal function (Table 1).

Diabetic patients and control subjects were personally provided with advice from a dietician to follow an identical isocaloric diet (comprising 50\% carbohydrates, 4 to $6 \mathrm{~g} \mathrm{NaCl}$ and $1.3 \mathrm{~g}$ per $\mathrm{kg}$ body weight protein daily content) at least 1 week before the studies. Daily intakes were controlled by electrolyte and urea nitrogen urinary excretion on 24-h samples prior to the study and precise protein intake was calculated from urea nitrogen urinary excretion, weight and Maroni's formula [20] (Table 1).

Study protocol. Renal functional reserve studies were performed on recumbent diabetic patients and control subjects. In order to achieve the required glycaemic stability, the patients were admitted to the hospital on the day before the test. Continuous s.c. insulin infusion was given with an external pump (Microjet Quark U100; Ames Dpt, Bayer Diagnostics, Miles, Elkart, Ind., USA) during the night and throughout the test. Blood glucose level was monitored every hour (One Touch II; Lifescan, Johnson and Johnson Co, Milpitas, Calif., USA) and the rate of insulin infusion was adapted to maintain the glycaemic level between 5.5 and $9.9 \mathrm{mmol} / \mathrm{l}$. On the morning of the study, a loading dose of $1000 \mathrm{mg}$ polyfructosan S (inulin, Inutest; Laevosan Gesellschaft, Linz, Austria) and $700 \mathrm{mg} p$-amino hippurate (PAH; Nephrotest; Biol. Arbeitsgem. GmbH, Lich, Germany) was administered i.v. Then, inulin (9 mg/min) and PAH (5.2 mg/min) were administered i.v. in a $5 \%$ dextrose solution to maintain plasma concentrations at $200 \mathrm{mg} / \mathrm{l}$ and $20 \mathrm{mg} / \mathrm{l}$ respectively throughout the study. A second indwelling venous cannula was used to deliver a $154 \mathrm{mmol} / \mathrm{l} \mathrm{NaCl}$ infusion in the other arm at a constant rate of $4 \mathrm{ml} / \mathrm{min}$. After a 60 -min equilibration period, a steady state of urine flow was obtained and a series of eight 60-min standard clearance periods were performed. After completion of two baseline periods, the $\mathrm{NaCl}$ solution was replaced by a $7.4 \%$ amino acid solution infused at the same rate of $4 \mathrm{ml} /$ min for $3 \mathrm{~h}$. The solution was made up of Azonutril 25 (Roger Bellon Laboratories, Neuilly sur Seine, France) diluted v/v with sterilized distilled water and conveying $300 \mathrm{mg} / \mathrm{min}$ of a mixture of $20 \mathrm{l}$-amino acids, i.e. approximately $4.5 \mathrm{mg}$ amino acids $\cdot \min ^{-1} \cdot \mathrm{kg}^{-1}$. Three clearance periods were performed during amino acid infusion. Then, the amino acid solution was replaced by the $\mathrm{NaCl}$ solution and three additional periods were obtained. Blood samples were taken at the midpoint of each clearance period and urine samples were collected by spontaneous voiding. Blood pressure and heart rate were monitored every 15 min during the study (Dynamap 1846 SX; Critikon, Tampa, Fla., USA).

Laboratory procedures and calculations. Plasma and urine levels of inulin and PAH were determined immediately, without any storage, by photocolorimetric methods. Creatinine levels were determined by the Jaffé reaction with picric acid using a kinetic method (Merckotest kits; Merck, Darmstadt, Germany). All absorbances were read on a Beckman DU 40 spectrophotometer (Fullerton, Calif., USA). Active renin concentra- tion (RIA with IRMA kits; Pasteur-Sanofi, Marne-la-Coquette, France) and aldosterone concentration (RIA with ALDO II kits; Sorin Biomedica, Saluggia, Italy) were measured in plasma samples from the baseline clearance periods before amino acid infusion.

Glomerular filtration rate (GFR) was equated with the clearance of inulin (C In) and effective renal plasma flow (ERPF) with the clearance of PAH (C PAH). RFR was equated with the difference between the higher GFR measured during amino acid infusion and baseline GFR. The filtration fraction was calculated as the ratio of $\mathrm{C}$ In to $\mathrm{C} \mathrm{PAH}$. Renal blood flow (RBF) was calculated as the ratio of ERPF to 1-haematocrit, and renal vascular resistance (RVR) was calculated as the ratio of mean arterial pressure $\mathrm{mm} \mathrm{Hg}$ to $\mathrm{RBF} 1 / \mathrm{min}$. All rates of filtration, flow and excretion as well as RVR are expressed per $1.73 \mathrm{~m}^{2}$ of body surface area. All fractional data are expressed as percentages.

Statistical analysis. Reported data before (baseline) and after (recovery) amino acid infusion represent the mean of that obtained during two and three consecutive clearance periods, respectively. Reported data during amino acid infusion (stimulation) represent the values obtained during the period of the higher level of GFR stimulation because RFR was calculated as the difference between the stimulated higher GFR and baseline GFR. This period of stimulated higher GFR was more often than not during the last hour of amino acid infusion in diabetic patients (30 times out of 33) as well as in control subjects (11 times out of 12). The values reported represent means \pm SEM. The results were processed by repeated variance analysis measurements. Differences between values obtained during baseline, stimulation and recovery periods, and between nA-nT, $\mu \mathrm{A}-\mathrm{nT}, \mathrm{mA}-\mathrm{hT}$ patients and control subjects were analysed using the Scheffe $F$-test for multiple comparisons. Differences inside groups of diabetic patients were analysed using the non-parametric Mann-Whitney $U$ test. Best-fit linear regression was evaluated using the least-squares method. Results with $p<0.05$ were considered statistically significant. Analysis of covariance was used to further evaluate the relative importance of independent variables on the dependent variable RFR. A significant $p$ value for the correlation between RFR and a variable would indicate that the latter affects RFR after adjusting for the contribution of the other variables.

\section{Results}

Mean baseline GFR in nA-nT patients was $133 \pm 3 \mathrm{ml} \cdot \mathrm{min}^{-1} \cdot 1.73 \mathrm{~m}^{-2}$ and significantly higher $(p<0.05)$ than in control subjects $(113 \pm 4 \mathrm{ml}$. $\min ^{-1} \cdot 1.73 \mathrm{~m}^{-2}$ ) (Fig. 1). It ranged from 118 to $149 \mathrm{ml} \cdot \min ^{-1} \cdot 1.73 \mathrm{~m}^{-2}$ and it could be considered that 5 patients out of 14 had a supranormal GFR that exceeded the value of basal controls by more than two standard deviations, i.e. higher than $140 \mathrm{ml} \cdot \mathrm{min}^{-1} \cdot 1.73 \mathrm{~m}^{-2}$. Mean baseline GFR did not differ between $\mu$ A-nT patients $(109 \pm 7$, range 72 to $135 \mathrm{ml} \cdot \mathrm{min}^{-1} \cdot 1.73 \mathrm{~m}^{-2}$ ) and control subjects because only 2 patients out of 10 had a GFR lower than that of control subjects by more than two standard deviations, i.e. lower than $86 \mathrm{ml} \cdot \mathrm{min}^{-1}$. $1.73 \mathrm{~m}^{-2}$. In contrast, mean GFR in $\mathrm{mA}-\mathrm{hT}$ patients $\left(78 \pm 8\right.$, range 38 to $107 \mathrm{ml} \cdot \mathrm{min}^{-1} \cdot 1.73 \mathrm{~m}^{-2}$ ) was sig- 


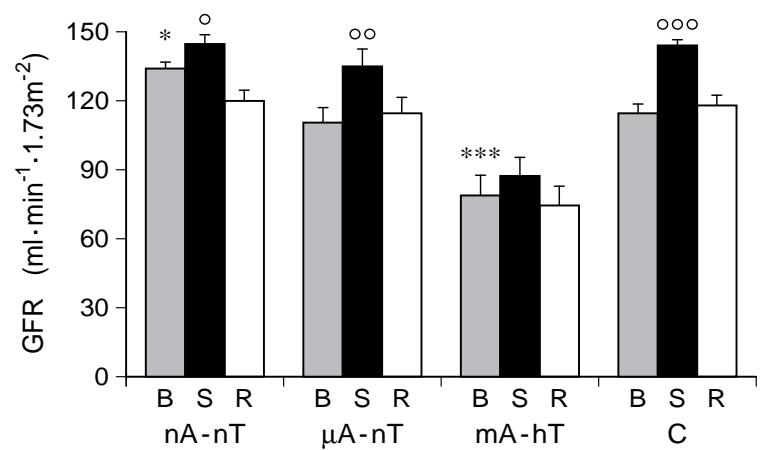

Fig. 1. Glomerular filtration rate (GFR) before (baseline, $B$ ), during (stimulation, $\mathrm{S}$ ) and after (recovery, R) amino acid infusion in 14 normoalbuminuric normotensive (nA-nT), 10 microalbuminuric-normotensive ( $\mu \mathrm{A}-\mathrm{nT})$ and 9 macroalbuminuric hypertensive (mA-hT) diabetic patients, and 12 control subjects $(C)$. Values represent means \pm SEM.

$* p<0.05, * * * p<0.001$ for differences with control subjects' baseline values ${ }^{\circ} p<0.05$, ${ }^{\circ o} p<0.01$, ${ }^{\circ o o} p<0.001$ for differences between stimulated and respective baseline values

nificantly lower than in control subjects $(p<0.001)$ (Fig. 1).

Stimulated GFR values during amino acid infusion were significantly higher than respective baseline values in $\mathrm{nA}-\mathrm{nT}$ patients $\left(143 \pm 5 \mathrm{ml} \cdot \mathrm{min}^{-1}\right.$ $\left.\cdot 1.73 \mathrm{~m}^{-2}, p<0.05\right), \mu \mathrm{A}-\mathrm{nT}$ patients $(133 \pm 8 \mathrm{ml}$. $\left.\min ^{-1} \cdot 1.73 \mathrm{~m}^{-2}, p<0.01\right)$ and control subjects $(142 \pm$ $\left.3 \mathrm{ml} \cdot \min ^{-1} \cdot 1.73 \mathrm{~m}^{-2}, p<0.001\right)$, but not in $\mathrm{mA}-\mathrm{hT}$ patients $\left(87 \pm 8 \mathrm{ml} \cdot \mathrm{min}^{-1} \cdot 1.73 \mathrm{~m}^{-2}\right)$ (Fig. 1). Amino acid-induced stimulation was fully reversible as evidenced by the fact that there was no difference between recovery and baseline GFR values. Linear regression analysis indicated that stimulated GFR was significantly and positively correlated with baseline GFR in diabetic patients $(y=0.94 x+21.17, r=0.84$, $p<0.001)$ as well as in control subjects $(y=0.58$ $x+76.37, r=0.85, p<0.001)$.

RFR was similar in $\mu$ A-nT patients $(24 \pm 6 \mathrm{ml}$. $\left.\min ^{-1} \cdot 1.73 \mathrm{~m}^{-2}\right)$ and control subjects $(28 \pm 2 \mathrm{ml}$. $\left.\min ^{-1} \cdot 1.73 \mathrm{~m}^{-2}\right)$ while representing $24 \pm 6$ and $25 \pm 3 \%$ of respective baseline GFR (Fig. 1). In contrast, RFR in nA-nT patients $\left(10 \pm 4 \mathrm{ml} \cdot \mathrm{min}^{-1}\right.$. $\left.1.73 \mathrm{~m}^{-2}\right)$ was significantly lower $(p<0.05)$ while representing only $8 \pm 3 \%$ of corresponding baseline GFR, and RFR was absent in mA-hT patients. RFR was significantly and inversely correlated to baseline GFR in control subjects $(y=-0.42 x+76.37$, $r=0.76, p<0.01$ ) indicating that the lower the GFR, the higher the RFR. Such a correlation could not be detected in diabetic patients $(r=0.10)$. Analysis of covariance revealed that patients' RFR was not affected by age $(p=0.93)$, sex $(p=0.56)$, diabetes duration $(p=0.66)$, daily insulin dosage $(p=0.97)$, urinary albumin excretion rate $(p=0.42)$, mean arterial pressure $(p=0.73)$ and baseline GFR $(p=0.19)$. In contrast, there was a significant "group effect" "

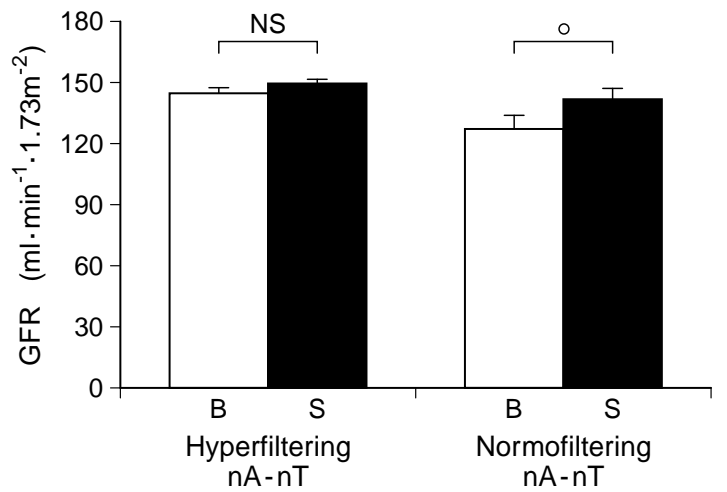

Fig. 2. Glomerular filtration rate (GFR) before (baseline, $B$ ) and during (stimulation, S) amino acid infusion in 5 hyperfiltering and 9 normofiltering nonalbuminuric normotensive diabetic patients (nA-nT). Values represent means \pm SEM.

NS not significant, ${ }^{\circ} p<0.05$ for differences between stimulated and respective baseline values

$(p<0.05)$ demonstrating that the major factor influencing RFR was the distribution of patients according to the usual bioclinical criteria. In particular, RFR appeared to be positively and independently associated as a categorical covariate with the microalbuminuric normotensive patient group.

In-depth analysis of our glomerular data also revealed two interesting points. 1) The effects of amino acid stimulation were inversely dependent on baseline GFR in nA-nT patients. Stimulated GFR $\left(149 \pm 7 \mathrm{ml} \cdot \mathrm{min}^{-1} \cdot 1.73 \mathrm{~m}^{-2}\right)$ was not significantly higher than baseline GFR $\left(145 \pm 2 \mathrm{ml} \cdot \mathrm{min}^{-1}\right.$. $1.73 \mathrm{~m}^{-2}$ ) and RFR was absent in the $5 \mathrm{nA}$-nT hyperfiltering patients (Fig.2). In contrast, stimulated GFR $\left(140 \pm 6 \mathrm{ml} \cdot \mathrm{min}^{-1} \cdot 1.73 \mathrm{~m}^{-2}\right)$ was significantly higher $(p<0.05)$ than baseline GFR $(126 \pm 2 \mathrm{ml}$. $\left.\min ^{-1} \cdot 1.73 \mathrm{~m}^{-2}\right)$ in the 9 normofiltering nA-nT patients whose RFR was thus $14 \pm 6 \mathrm{ml} \cdot \mathrm{min}^{-1}$. $1.73 \mathrm{~m}^{-2}$. And, 2) in $\mu \mathrm{A}-\mathrm{nT}$ patients, no difference in results was detected between those whose usual CEI therapy had been interrupted 1 week before the study and those who had never been submitted to CEI: neither baseline GFR (109 \pm 7 vs $109 \pm 13 \mathrm{ml}$. $\left.\min ^{-1} \cdot 1.73 \mathrm{~m}^{-2}\right)$ nor RFR $(29 \pm 7$ vs $19 \pm 9 \mathrm{ml}$. $\min ^{-1} \cdot 1.73 \mathrm{~m}^{-2}$ ) differed significantly between the 5 CEI-previously treated and the 5 CEI-untreated $\mu \mathrm{A}-\mathrm{nT}$ patients respectively.

Data for mean arterial pressure, ERPF and filtration fraction are presented in Table 2. Baseline arterial pressure in $\mathrm{mA}-\mathrm{hT}$ patients was significantly higher than in control subjects $(p<0.001)$. Mean pressure was not significantly altered in diabetic patients or control subjects during amino acid infusion. Although higher in nA-nT and $\mu \mathrm{A}-\mathrm{nT}$ patients, and lower in $\mathrm{mA}$-hT patients, baseline ERPF was not significantly different from that in control subjects. During amino acid infusion, ERPF did not change in $\mathrm{mA}-\mathrm{hT}$ patients whereas it increased in $\mathrm{nA}-\mathrm{nT}$ and $\mu \mathrm{A}-\mathrm{nT}$ 
Table 2. Effects of amino acid infusion (Stimulation) on mean arterial pressure, effective renal plasma flow (ERPF) and filtration fraction in IDDM patients and control subjects (C)

\begin{tabular}{lccc}
\hline & Baseline & Stimulation & Recovery \\
\hline $\begin{array}{l}\text { Mean arterial pressure } \\
\text { (mm Hg) }\end{array}$ & & & \\
$\mathrm{nA}-\mathrm{nT}$ & $77 \pm 2$ & $78 \pm 5$ & $76 \pm 2$ \\
$\mu \mathrm{A}-\mathrm{nT}$ & $85 \pm 3$ & $81 \pm 3$ & $83 \pm 3$ \\
$\mathrm{~mA}-\mathrm{hT}$ & $111 \pm 5^{\mathrm{b}}$ & $114 \pm 5^{\mathrm{b}}$ & $108 \pm 4^{\mathrm{b}}$ \\
$\mathrm{C}$ & $80 \pm 2$ & $78 \pm 6$ & $80 \pm 2$ \\
$\mathrm{ERPF}\left(\mathrm{ml} \cdot \mathrm{min}^{-1} \cdot 1.73 \mathrm{~m}^{-2}\right)$ & & & \\
$\mathrm{nA}-\mathrm{nT}$ & $596 \pm 37$ & $630 \pm 46$ & $534 \pm 30$ \\
$\mu \mathrm{A}-\mathrm{nT}$ & $566 \pm 39$ & $626 \pm 66$ & $489 \pm 46$ \\
$\mathrm{~mA}-\mathrm{hT}$ & $487 \pm 53$ & $487 \pm 51$ & $441 \pm 49$ \\
$\mathrm{C}$ & $533 \pm 31$ & $584 \pm 29$ & $536 \pm 19$ \\
Filtration fraction $(\%)$ & & & \\
$\mathrm{nA}-\mathrm{nT}$ & $23.3 \pm 1.3$ & $24.0 \pm 1.6$ & $22.9 \pm 0.9$ \\
$\mu \mathrm{A}-\mathrm{nT}$ & $19.7 \pm 1.4$ & $22.1 \pm 1.0$ & $24.1 \pm 1.5$ \\
$\mathrm{~mA}-\mathrm{hT}$ & $16.5 \pm 1.4^{\mathrm{a}}$ & $18.2 \pm 1.2^{\mathrm{a}}$ & $17.8 \pm 2.5$ \\
$\mathrm{C}$ & $22.0 \pm 1.4$ & $24.3 \pm 1.3$ & $21.8 \pm 0.7$ \\
\hline Values are means \pm SEM & & & \\
${ }^{\mathrm{a}} p<0.05,{ }^{\mathrm{b}} p<0.001$ vs control subjects & & \\
& & &
\end{tabular}

patients as well as in control subjects although the difference with the respective baseline values was not significant. Baseline filtration fraction did not differ between nA-nT patients, $\mu \mathrm{A}-\mathrm{nT}$ patients and control subjects, and was significantly lower in mA-hT patients $(p<0.05)$. The consistent tendency of filtration fraction to increase during stimulation was not significant in either diabetic patients or control subjects.

Although slightly lower, calculated baseline RVR in nA-nT patients $\left(78 \pm 5 \mathrm{~mm} \mathrm{Hg} \cdot \mathrm{l}^{-1} \cdot \mathrm{min}^{-1}\right.$. $1.73 \mathrm{~m}^{-2}$ ) did not differ significantly from RVR in $\mu \mathrm{A}-\mathrm{nT}$ patients and control subjects which were similar $\left(88 \pm 6\right.$ and $90 \pm 7 \mathrm{~mm} \mathrm{Hg} \cdot \mathrm{l}^{-1} \cdot \mathrm{min}^{-1} \cdot 1.73 \mathrm{~m}^{-2}$, respectively) (Fig. 3). RVR was significantly higher $(p<0.01)$ in $\mathrm{mA}-\mathrm{hT}$ patients $\left(155 \pm 21 \mathrm{~mm} \mathrm{Hg} \cdot \mathrm{l}^{-1}\right.$. $\left.\min ^{-1} \cdot 1.73 \mathrm{~m}^{-2}\right)$. RVR was decreased by amino acid infusion in both $\mu \mathrm{A}-\mathrm{nT}$ patients (by $\left.9 \pm 4 \mathrm{~mm} \mathrm{Hg} \cdot \mathrm{l}^{-1} \cdot \mathrm{min}^{-1} \cdot 1.73 \mathrm{~m}^{-2}, p<0.05\right)$ and control subjects (by $11 \pm 4 \mathrm{~mm} \mathrm{Hg} \cdot \mathrm{l}^{-1} \cdot \mathrm{min}^{-1} \cdot 1.73 \mathrm{~m}^{-2}$, $p<0.05$. In striking contrast, RVR was not significantly altered by stimulation in nA-nT (-2 \pm $\left.4 \mathrm{~mm} \mathrm{Hg} \cdot \mathrm{l}^{-1} \cdot \min ^{-1} \cdot 1.73 \mathrm{~m}^{-2}\right)$ or $\mathrm{mA}-\mathrm{hT}$ patients $\left(+8 \pm 9 \mathrm{~mm} \mathrm{Hg} \cdot \mathrm{l}^{-1} \cdot \mathrm{min}^{-1} \cdot 1.73 \mathrm{~m}^{-2}\right)$.

\section{Discussion}

This study documents specific characteristics of the renal functional reserve induced by an amino acid infusion in IDDM patients at different stages of the disease. Our observations provide evidence that, compared with healthy control subjects, the ability to vasodilate and demonstrate an RFR is reduced in nonalbuminuric normotensive patients, normal in microalbuminuric normotensive patients and absent in macroalbuminuric hypertensive patients, all in simi-

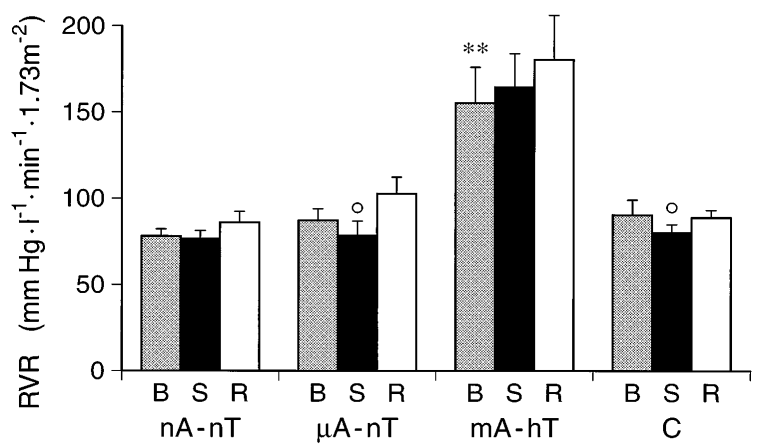

Fig.3. Renal vascular resistance (RVR) before, during and after amino acid infusion. B, S, R, nA-nT, $\mu \mathrm{A}-\mathrm{nT}$, mA-hT and $\mathrm{C}$ are as in Figure 1. Values represent means \pm SEM.

$* * p<0.01$ for differences with control subjects' baseline values ${ }^{\circ} p<0.05$ for differences between stimulated and respective baseline values

lar metabolic control and with similar sodium and protein intakes.

Differences in experimental conditions between subjects were suppressed as far as possible in the study protocol to prevent any influence on the results while meeting clinical requirements. Sodium and protein intakes were standardized, and CEI therapy was interrupted at least 1 week before the day of the study. Infusion rates were similar for all subjects. The result was that protein intake, baseline urine flow rate, urinary sodium excretion rate as well as plasma renin and aldosterone levels did not differ significantly between groups of patients and between patients and healthy control subjects. In addition, no difference in results was detected between $\mu \mathrm{A}-\mathrm{nT}$ patients whose CEI therapy had been interrupted 1 week before the study and those who had never been submitted to CEI. Finally, analysis of covariance clearly establishes that the major factor influencing renal reserve in our study is the stage of renal involvement as determined classically by the prevailing levels of proteinuria and blood pressure.

A renal reserve exists but is reduced in non-albuminuric-normotensive patients with recently diagnosed diabetes considered as a unique group with significantly elevated mean basal GFR. A supranormal GFR is a constant feature of early experimental diabetes in streptozotocin-treated rats [21, 22], alloxan diabetic rats [23], pancreatectomized dogs [24], and strains of spontaneously diabetic rats [25]. Numerous studies have also detected a frequent GFR increment in newly diagnosed and/or short-term human diabetes [26--31]. Whatever the haemodynamic and humoral mechanisms of glomerular hyperfiltration [32--35], our data demonstrate that the RFR reduction in $\mathrm{nA}$ $\mathrm{nT}$ patients directly results from the supranormal baseline GFR since: 1) Amino acid infusion was unable to elicit any additional renal vasodilation as demonstrated by the fact that it did not significantly 
alter the mean renal resistance. 2) The response to stimulation differed strikingly between $\mathrm{nA}-\mathrm{nT}$ patients according to basal GFR value: the low mean RFR of the whole group is clearly due to the 5 patients with supranormal basal GFR who were deprived of renal reserve. 3) The stimulated GFR during amino acid infusion did not differ between nA-nT patients and control subjects demonstrating that the overall ability of the kidney to vasodilate is not really increased in early diabetes. Part of this ability is merely brought into play in the basal condition, thus narrowing the gap between baseline and stimulated values and decreasing the renal reserve at this silent stage of the disease.

In microalbuminuric normotensive patients, basal GFR and RVR, stimulated GFR, and RFR mean values were not significantly different from those in control subjects since only in 2 patients was GFR slightly decreased. This similarity indicates that whole kidney glomerular hyperfiltration could no longer be detected in the patients who had lived with diabetes for approximately 17 years and were considered to be in the incipient stage of diabetic nephropathy. It also establishes that the kidney's ability to vasodilate and demonstrate RFR is not reduced. Covariance analysis confirmed that RFR is positively and independently associated as a categorical covariate with the $\mu \mathrm{A}-\mathrm{nT}$ patient group. Despite the general acceptance of the existence of glomerular structural changes at this stage, it has been emphasized that these lesions can be regularly observed in the kidneys of patients with long-standing diabetes who have little or no clinical disease, and that these lesions are indicative of chronic diabetes but do not necessarily denote significant renal dysfunction $[36,37]$. Our results tie up with this interpretation and clearly demonstrate that there is no relative hyperfiltration or irreversible glomerular functional impairment at this incipient microalbuminuric stage of diabetic nephropathy.

In contrast, macroalbuminuric hypertensive patients had moderate renal insufficiency with significantly lower basal GFR and higher renal resistance representing approximately $172 \%$ of RVR in control subjects. Amino acid infusion did not elicit either a GFR increase or an RVR decrease in mA-hT patients. These patients were significantly older than control subjects. If one agrees that a decline in renal function is found in elderly subjects, this might be responsible, at least in part, for the difference between them and control subjects. In fact, linear regression as well as covariance analysis indicates that renal reserve was not affected by age in our study. Moreover, all of the previous three studies on healthy elderly subjects and non-nephrologically ill elderly patients have consistently demonstrated that an intact RFR can be elicited in humans at an advanced age by either an amino acid infusion [38, 39] or a meat meal [40]. Therefore the difference in age between $\mathrm{mA}-\mathrm{hT}$ patients and control subjects is not likely to explain the lower RFR in the former. It is worth pointing out that it would have been difficult to predict the likely pathologic lesions of overt nephropathy $[36,37]$ and the suppressed RFR from a normal serum creatinine level, an almost normal creatinine clearance and a remarkably well preserved mean basal GFR. Several studies by others and ourselves have demonstrated that a proportionally normal RFR could still be elicited in subjects with a lower baseline GFR than that of our $\mathrm{mA}$-hT diabetic patients, for instance in uninephrectomized healthy subjects and kidney transplant recipients $[41,42]$ or in subjects with non-diabetic chronic renal diseases [1, 43--47]. Whatever the inner pathologic mechanism [48, 49], the glomerular filtration process appears to be impressively well-protected in overt diabetic nephropathy, at the very time when an irreversible glomerular functional impairment is evidenced by the increased resistance and by the suppressed ability to vasodilate and demonstrate an RFR. In this respect, invariability of amino acidstimulated GFR and absence of an RFR clearly appear to provide more sensitive assessments of the functional renal damage in clinical overt diabetic nephropathy than usual baseline evaluation.

It is generally agreed that the existence of an RFR indicates that all nephrons are not functioning at their maximum capacity and that the kidneys do not exhibit permanent hyperfiltration. Our results clearly indicate that microalbuminuric normotensive diabetic patients with incipient nephropathy retain a normal renal reserve whereas, paradoxically, RFR is reduced or suppressed at two opposite stages of the disease: in normoalbuminuric normotensive patients with supranormal GFR at the stage of silent renal involvement, and in macroalbuminuric hypertensive patients with moderately reduced GFR at the overt nephropathy stage. The main outcome of the study is therefore that RFR in IDDM is dependent on the basal GFR value but in a way which is quite different from that in non-diabetic glomerular diseases. During the preclinical stages, the maximum ability of kidney to vasodilate is neither reduced nor increased but similar to that in healthy subjects as demonstrated by identical amino acid-stimulated GFRs; consequently, RFR is reduced at the silent stage with elevated basal GFR and is intact at the incipient stage with normal GFR. During the clinical stage, the reduced ability of the kidney to vasodilate accounts for an irreversible functional impairment in spite of remarkably well-preserved GFR. These characteristic features of the response to amino acid stimulation also explain why RFR is not correlated to baseline GFR in diabetic patients, unlike in our healthy control subjects or in healthy and diseased subjects who provided an extended range of baseline values for GFR [50].

Whether or not glomerular hyperfiltration expressed by the reduction of the loss of RFR plays a role 
in the progression of renal damage is a critical question, especially in patients with early diabetes. It has been reported that early functional changes might relate to the development of glomerulopathy in rats with streptozotocin-induced diabetes [51] as well as in diabetic patients [52--55]. Experimentally, intervention such as uninephrectomy or increasing dietary protein content -- which aggravate glomerular capillary perfusion, pressure and filtration -- accelerate the development of glomerular injury. Furthermore, patients with the highest values for GFR in the early stage of diabetes are more likely to progress to persistent albuminuria or overt nephropathy. An 8-year prospective study in initially normoalbuminuric patients has even revealed initial GFR as the only significant independent predictor for nephropathy [55]. Conversely, an intervention such as dietary protein restriction, which improves the haemodynamic changes, may favourably influence the natural history of the disease. Serial studies of renal function and repeated evaluation of the RFR in diabetic patients who exhibited or did not exhibit glomerular hyperfiltration during the early stage of the disease may allow conclusive new insights to be gained on the subject. Another most interesting group is composed of patients with very long-lasting IDDM who, nevertheless, exhibit no sign of diabetic nephropathy. Whether or not these patients are characterized by an intact RFR is currently being examined.

We conclude that microalbuminuric normotensive diabetic patients retain a normal RFR whereas RFR is reduced in normoalbuminuric normotensive patients with supranormal GFR, and suppressed in macroalbuminuric hypertensive patients with reduced GFR. In particular, the normal response to amino acids in microalbuminuric normotensive patients suggests that the loss of renal functional reserve is not an early phenomenon during diabetic renal disease.

Acknowledgements. This study was supported by grants from the Paul Sabatier University and the Institut National de la Santé et de la Recherche Médicale.

\section{References}

1. Bosch JP, Lew S, Glabman S, Lauer A (1986) Renal hemodynamic changes in humans. Response to protein loading in normal and diseased kidney. Am J Med 81: 809--815

2. Hostetter TH (1986) Human renal response to a meat meal. Am J Physiol 250: F613--F618

3. terWee PM, Rosman JB, Van Der Geest S, Sluiter WJ, Donker AJM (1986) Renal hemodynamics during separate and combined infusion of amino acids and dopamine. Kidney Int 29: 870--874

4. Woods LL, Mizelle HL, Montani JP, Hall JE (1986) Mechanisms controlling renal hemodynamics and electrolyte excretion during amino acids. Am J Physiol 251: F303--F312
5. Memoli B, Libetta C, Sabbatini M et al. (1991) Renal functional reserve: its significance in normal and salt depletion conditions. Kidney Int 40: 1134--1140

6. Brenner BM, Meyer TW, Hostetter TH (1982) Dietary protein intake and the progessive nature of kidney disease: the role of hemodynamically mediated glomerular injury in the pathogenesis of progessive glomerular sclerosis in aging, renal ablation, and intrinsic renal disease. $\mathrm{N}$ Engl $\mathrm{J}$ Med 307: $652--659$

7. Jones SL, Viberti GC (1995) Renal functional reserve in subjects with diabetes mellitus. Seminar Nephrol 15: 475-481

8. Castellino P, De Santo NG, Capasso G et al. (1989) Low protein alimentation normalizes renal haemodynamic response to acute protein ingestion in type 1 diabetic children. Europ J Clin Invest 19: 78--83

9. Nosadini R, Trevisan R, Fioretto P et al. (1989) Kidney hemodynamics after ketone body and amino acid infusion in normal and IDDM subjects. Diabetes 38: 75--83

10. Fioretto P, Trevisan R, Valerio A et al. (1990) Impaired renal response to a meat meal in insulin-dependent diabetes: role of glucagon and prostaglandins. Am J Physiol 258: F675--F683

11. Brouhard BH, LaGrone L (1990) Effect of dietary protein restriction on functional renal reserve in diabetic nephropathy. Am J Med 89: 427--431

12. Pinto JR, Bending JJ, Dodds RA, Viberti GC (1991) Effect of low protein diet on the renal response to meat ingestion in diabetic nephropathy. Europ J Clin Invest 21: 175-183

13. Jones SL, Kontessis P, Wiseman M et al. (1992) Protein intake and blood glucose as modulators of GFR in hyperfiltering diabetic patients. Kidney Int 41: 1620--1628

14. ter Wee PM, van Ballegooie E, Rosman JB, Meijer S, Donker AJM (1987) Renal reserve filtration capacity in patients with type 1 (insulin-dependent) diabetes mellitus. Nephrol Dial Transplant 2: 504--509

15. Slomowitz LA, Hirschberg R, Kopple JD (1988) Captopril augments the renal response to an amino acid infusion in diabetic adults. Am J Physiol 255: F755--F762

16. Bilo HJG, van Ballegooie E, Hazenberg HJA, Gans ROB, Donker AJM (1991) Renal function and renal function reserve in insulin-dependent diabetic patients during (near) normoglycaemia. Nephron 91: 295--299

17. Tuttle KR, Bruton JL, Perusek MC et al. (1991) Effect of strict glycemic control on renal hemodynamic response to amino acids and renal enlargement in insulin-dependent diabetes mellitus. N Engl J Med 324: 1626--1632

18. Mogensen CE (1989) Natural history of renal functional abnormalities in human diabetes mellitus: from normoalbuminuria to incipient and overt nephropathy. In: Brenner BM, Stein JH (eds) The kidney in diabetes mellitus. Contemporary issues in nephrology, Vol 20. Churchill Livingstone, New York Edinburgh London Melbourne, pp 19--49

19. Hostetter TH (1991) Diabetic nephropathy. In: Brenner BM, Rector FC (eds) The kidney. 4th edn. WB Saunders, Philadelphia, pp 1695--1727

20. Maroni BJ, Steinman TI, Mitch WE (1985) A method for estimating nitrogen intake of patients with chronic renal failure. Kidney Int 27: 58--65

21. Hostetter TH, Troy JL, Brenner BM (1981) Glomerular hemodynamics in experimental diabetes mellitus. Kidney Int 19: 410--415

22. Jensen PK, Christiansen JS, Steven K, Parving HH (1981) Renal function in streptozotocin-diabetic rats. Diabetologia 21: 409--414 
23. Michels LD, Davidman M, Keane WF (1981) Determinants of glomerular filtration and plasma flow in experimental diabetic rats. J Lab Clin Med 98: 869--885

24. del Castillo E, Fuenzalida R, Uranga J (1977) Increased glomerular filtration rate and glomerulopressin activity in diabetic dogs. Horm Metab Res 9: 46--53

25. Okwueze MI, Opgenorth TJ, von Geldern TW, Vari RC (1994) Atrial natriuretic peptide and glomerular hyperfiltration during onset of spontaneous diabetes mellitus. Am J Physiol 266: R572--R577

26. Fiaschi E, Grassi B, Andres G (1952) La funzione renale nel diabete mellito. Rassegna di Fisiopatologia Clin Terap 4: $373--410$

27. Stalder G, Schmid R (1959) Severe functional disorders of glomerular capillaries and renal hemodynamics in treated diabetes mellitus during childhood. Ann Paediatr (Basel) 193: $129--138$

28. Mogensen CE (1971) Kidney function and glomerular permeability to macromolecules in early juvenile diabetes. Scand J Clin Lab Invest 28: 79--90

29. Mogensen CE (1986) Early glomerular hyperfiltration in insulin-dependent diabetics and late nephropathy. Scand J Clin Lab Invest 46: 201--206

30. Mogensen CE, Hansen KW, Nielsen S, Mau Pedersen M, Rehling M, Schmitz A (1993) Monitoring diabetic nephropathy: glomerular filtration rate and abnormal albuminuria in diabetic renal disease -- Reproducibility, progression, and efficacy of antihypertensive intervention. Am J Kidney Dis 22: 174--187

31. Ditzel J, Schwartz M (1967) Abnormally increased glomerular filtration rate in short-term insulin-treated diabetic subjects. Diabetes 16: 264--267

32. Anderson S (1989) Pathogenesis of diabetic glomerulopathy: hemodynamic factors. In: Brenner BM, Stein JH (eds) The kidney in diabetes mellitus. Contemporary issues in nephrology, Vol 20. Churchill Livingstone, New York Edinburgh London Melbourne, pp 67--85

33. Ziyadeh FN, Goldfarb S, Kern EFO (1989) Diabetic nephropathy: metabolic and biochemical mechanisms. In: Brenner BM, Stein JH (eds) The kidney in diabetes mellitus. Contemporary issues in nephrology, Vol 20. Churchill Livingstone, New York Edinburgh London Melbourne, pp 87--113

34. Bank N (1991) Mechanisms of diabetic hyperfiltration. Kidney Int 40: 792--807

35. Mogyorosi A, Ziyadeh FN (1996) Update on pathogenesis, markers and management of diabetic nephropathy. Current Opinion Nephrol Hypertension 5: 243--253

36. Hostetter TH, Daniels BS (1989) Natural history of renal structural abnormalities in diabetes mellitus. In: Brenner BM, Stein JH (eds) The kidney in diabetes mellitus. Contemporary issues in nephrology, Vol 20. Chuchill Livingstone, New York Edinburgh London Melbourne, pp 51--65

37. O'Donnell MP, Kasiske BL, Keane WF (1988) Glomerular hemodynamic and structural alterations in experimental diabetes mellitus. FASEB J 2: 2339--2347

38. Böhler J, Glöer D, Reetze-Bonorden P, Keller E, Schollmeyer PJ (1993) Renal functional reserve in elderly patients. Clin Nephrol 39: 145--150
39. Fliser D, Seier M, Nowack R, Ritz E (1993) Renal functional reserve in healthy elderly subjects. J Am Soc Nephrol 3: 1371--1377

40. De Santo NG, Anastasio P, Coppola S, Barba G, Jadanza A, Capasso G (1991) Age-related changes in renal reserve and renal tubular function in healthy humans. Child Nephrol Urol 11: 33--40

41. Ader JL, Tack I, Lloveras JJ et al. (1994) Renal functional reserve in cyclosporine-treated recipients of kidney transplant. Kidney Int 45: 1657--1667

42. Ader JL, Tack I, Durand D, Tran-Van T, Rostaing L, Suc JM (1996) Renal functional reserve in cyclosporine-treated kidney and heart transplant recipients. J Am Soc Nephrol 7: 1145--1152

43. Chan AYM, Cheng MLL, Keil LC, Myers BD (1988) Functional response of healthy and diseased glomeruli to a large, protein-rich meal. J Clin Invest 81: 245--254

44. Bilo HJG, Schaap GH, Blaak E, Gans ROB, Oe PL, Donker AJM (1989) Effects of chronic and acute protein administration on renal function in patients with chronic renal insufficiency. Nephron 53: 181--187

45. Kishna GG, Kapoor SC (1991) Preservation of renal reserve in chronic renal disease. Am J Kidney Dis 17: 18--24

46. De Santo NG, Capasso G, Anastasio P et al. (1990) The renal hemodynamic response following a meat meal in children with chronic renal failure and in healthy controls. Nephron 56: 136--142

47. terWee PM (1995) Renal effects of intravenous amino acid administration in humans with and without renal disease: hormonal correlates. Sem Nephrol 15: 426--432

48. Osterby R, Parving HH, Hommel E, Jorgensen HE, Lokkegaard H (1990) Glomerular structure and function in diabetic nephropathy. Diabetes 39: 1057--1063

49. Osterby R, Parving HH, Nyberg G et al. (1988) A strong correlation between glomerular filtration rate and filtration surface in diabetic nephropathy. Diabetologia 31: 265--270

50. Hoogenberg K, terWee PM, Lieverse AG, Sluiter WJ, Dullaart RPF (1994) Insulin-like growth factor I and altered renal hemodynamics in growth hormone deficiency, acromegaly, and type I diabetes mellitus. Transplant Proc 26: 505--507

51. Zatz R, Meyer TW, Rennke HG, Brenner BM (1985) Predominance of hemodynamic rather than metabolic factors in the pathogenesis of diabetic glomerulopathy. Proc Natl Acad Sci USA 82: 5963--5967

52. Brenner BM, Hostetter TH, Olson JL, Rennke HG, Vankatachalam MA (1981) The role of glomerular hyperfiltration in the initiation and progression of diabetic nephropathy. Acta Endocrinol [Suppl 242]: 7--10

53. Hostetter TH, Rennke HG, Brenner BM (1982) The case of intrarenal hypertension in the initiation and progression of diabetic and other glomerulopathies. Am J Med 72: 375--380

54. Mogensen CE, Christensen CK (1984) Predicting diabetic nephropathy in insulin-dependent patients. N Engl J Med 311: 89--93

55. Rudberg S, Persson B, Dahlquist G (1992) Increased glomerular filtration rate as a predictor of diabetic nephropathy -- An 8-year prospective study. Kidney Int 41: 822--828 